\title{
The organizational process in construction using information modeling technologies
}

\author{
Marat Kuzhin ${ }^{1, *}$, Boris Zhadanovsky ${ }^{1}$, Mark Kudryashov ${ }^{1}$ and Elena Granilshchikova ${ }^{1}$ \\ ${ }^{1}$ Moscow State University of Civil Engineering, 129337 Moscow, Russia
}

\begin{abstract}
The development trend of the construction industry has contributed to the expansion of scientific and applied research in the development and introduction of new forms, methods and systems in order to increase competitiveness and efficiency. The transition of the industrial and civil construction industry to a higher level of competitiveness in many countries of the world is associated with the creation of full-fledged BIM-models. The object of this article is the use of BIM-modeling in the organizational-technological process. The relevance of this topic is high, since the introduction of BIM technology in Russia allows to solve a number of problems: the number of reworkings is reduced, the number of errors decreases, the number of information gaps becomes less. The purpose of this article is to clarify and clarify the essence of BIM-technology, identify positive aspects of the implementation of this technology in the organization of the construction industry, and also provide examples of BIM implementation in domestic organizations in Russia using the method of collecting and processing information. The result of this study is analytical conclusions on the subject under study. The practical significance of the article lies in its analytical approach to BIMmodeling
\end{abstract}

\section{Introduction}

Information model of a construction is a process of team creation of a three-dimensional model building of a designed construction to extract information from it. Model is associated with information database, each element in which it is possible to assign additional attributes. This information can be used in further operations and stored throughout its full life cycle. A characteristic feature of software systems is that the object is actually designed as a whole. Changing one of the parameters leads to an automatic changing of other related parameters. Under the information modeling or BIM (Building Information Modeling) today in the design refers to a three-dimensional model of an existing or prepared for the construction of the object, the distinctive features of which are:

-the relationship of all elements with each other;

-admissibility of addition, change, analysis and forecasting of development;

-planning the project of a relative real place;

\footnotetext{
* Corresponding author: kuzhinmf@mail.ru
} 
-the ability to bind the project to time;

-the possibility of simultaneous performance of work in one project by specialists of different directions and specialties, using a common network

From this determine the main advantages of the use of BIM. Among the benefits of using BIM-models are listed:

-the ability to automate the development of design documentation of high quality;

-minimum number of errors and misprints in the drawings, calculations, graphs, specifications, estimates;

- current information on the operational and price indicators of materials;

-visualization of the construction, which allows you to choose the technical solution;

-ease of managing the construction and operation of the object;

-the availability of current data for the possibility of reconstruction, technical modernization and demolition of buildings and structures at the end of their life cycle.

One of the main components of BIM modeling is to simulate the construction process, in other words, it is possible to model the construction work on a computer, which presents an opportunity for all project participants to see the implementation of their ideas and coordinate them with other participants, as well as with the performer. It is also possible to simulate the operation of the construction site, which allows you to track the work of the equipment calculated by the project and draw conclusions about the satisfaction of its parameters.

BIM technologies are the process of creating, modifying, and subsequently using a virtual copy of a structure, containing all the information about it. This technology is based on the virtual three-dimensional model with real physical properties. This model combines the data of architectural planning, structural, economic, technological, operational characteristics of the object, which are interrelated and interdependent. Also, additional measurements are added to the BIM model: 4D BIM (Building sequence), 5D BIM (Cost), 6D BIM (Lifecycle Information).

Today, customers prefer to see different versions of the project, know exactly the cost of construction and at the same time clearly understand what they are paying for. 3Dvisualization allows you to beautifully submit a project to the customer and find the best design solutions to replace old ones.

Based on the results of research conducted in Russia and abroad, the introduction of BIM can significantly improve the performance of the design and construction industry, improve competitiveness at the global level. BIM-modeling will help achieve the goals set in the Innovative Development Strategy of the construction industry of the Russian Federation until 2030, which, in turn, will increase the efficiency of the industry and improve the quality of construction products.

Today, speaking of BIM-modeling, most often have in mind the use of information models at the design stage. But these technologies help to optimize work not only at this stage, but also at the stages of construction and operation. BIM allows you to control an object at all stages of its life cycle. The purpose of this article is a deeper consideration of BIM-technologies in the organization of construction production.

When writing this article, methods of collecting and processing information were used through theoretical tools for analyzing scientific works (articles, monographs, textbooks), direct use of data through citing, indirect use of data through editing, aggregation and transformation into a new form. 


\section{Advantages of the BIM model in the organization of the construction industry}

BIM technology allows you to calculate and determine the parameters of the construction process even before the start of construction work on the object. Having created such a project, it is possible to assess the internal and external appearance of the building, financial costs, material requirements and the amount of labor, the composition of the necessary equipment and the organization of the construction process. Information from information models helps to create a preliminary visualization of work processes, which significantly increases the efficiency of construction work.

The model contains specification catalogs that determine the effort required to create a project. This means that it is possible to automate the creation of network models and schedules. This will significantly reduce the time required for the preparation of organizational and technological documentation. Automated development of projects makes it possible to obtain more accurate information and in a short time to make changes to projects. Also in the model are available financial indicators. The estimated cost of the project is determined immediately after making changes to it.

One of the most important advantages of the information modeling technology is the absence of collisions in the design documentation and, as a result, in the working documentation. The discrepancy between different sections of the project is eliminated since all the nodes are designed in the BIM model and engineering systems are linked. Also, the advantage is that you can get all the drawings in minutes.

Information modeling technologies make it possible to achieve well-coordinated work on construction sites: duties are clearly distributed between teams, the accuracy of the schedules for the procurement of materials and equipment is minimized. The management easily controls the cash flow - all expenses are monitored, all prices are recorded. Each employee can look at the cost estimate or check the accounting report. Thanks to the information model, builders can control the process of erection of a structure, follow the delivery and production time.

BIM technology allows you to optimize the construction plan. For example, cranes work on neighboring houses. If their graphics match, they can "meet the arrows." And no one took this into account, because the equipment belongs to different owners, and it is unlikely that someone will manually compare the mode of operation of various mechanisms. And on the visual chart you will see what the optimal load is required for a particular construction machine, whether there is an advance or lag. You can calculate what money you need to invest in the construction at each of the stages.

The information model is a visual model of how we build. It allows you to zoning the construction site: allocate areas for household and residential towns, under the dump of soil, temporary storage of materials and equipment. It is more rational to dispose of construction equipment, to reduce the number of crane equipment, for example, a tower crane. This seriously affects the economics of the construction site.

Recently there are more and more new software packages, as well as their updates. Experts say that soon a growing number of companies will use software beyond the limits of three-dimensional modeling, which will allow companies to provide more information about the designed object. Now they are beginning to use $4 \mathrm{D}, 5 \mathrm{D}$, as well as $6 \mathrm{D}$ measurements for construction objects. With each new dimension, the project receives more information, now it is not only the information model of the building, but also the time of its construction. Opportunities for new measurements:

-allows you to see what the planned building (structure) will look like even before construction begins. More accurate development of drawings and other design documentation, automatic fulfillment of material specifications, etc.; 
-adds a binding to the time, increases the accuracy of the planning;

-add the amount of projecting the amount of costs (you can find out the price of the object without special estimated calculations);

-the consumption of resources (consumption of electricity, heat supply and other important resources), generation of the building life cycle is added;

- design which helps to see the operational and technical indicators of the designed object. This allows you to see the need for examination of the building after some time after construction.

Information modeling software at the construction stage is divided into four categories:

- software that allows you to check the building model for errors and deviations from the design model of the building;

- software for viewing the building model;

- software for the implementation of the document flow process between the construction participants;

- software for planning and control of construction works;

- software that allows quality control of the progress of construction [2].

Each new level, which is added to the technology of information modeling, allows you to increase the benefits of money invested in the construction.

The technology of visual planning as part of BIM allows you to develop variants of organizational and technological solutions and compare them with each other. For example, in the construction, three technologies were proposed: large-sized mounting, ring mounting and mounting from small transportable segments. On the basis of a unified approach to estimating the number of necessary personnel and equipment necessary to perform these works, they came to the conclusion that the variant with segments is almost a year faster than the variant with petals.

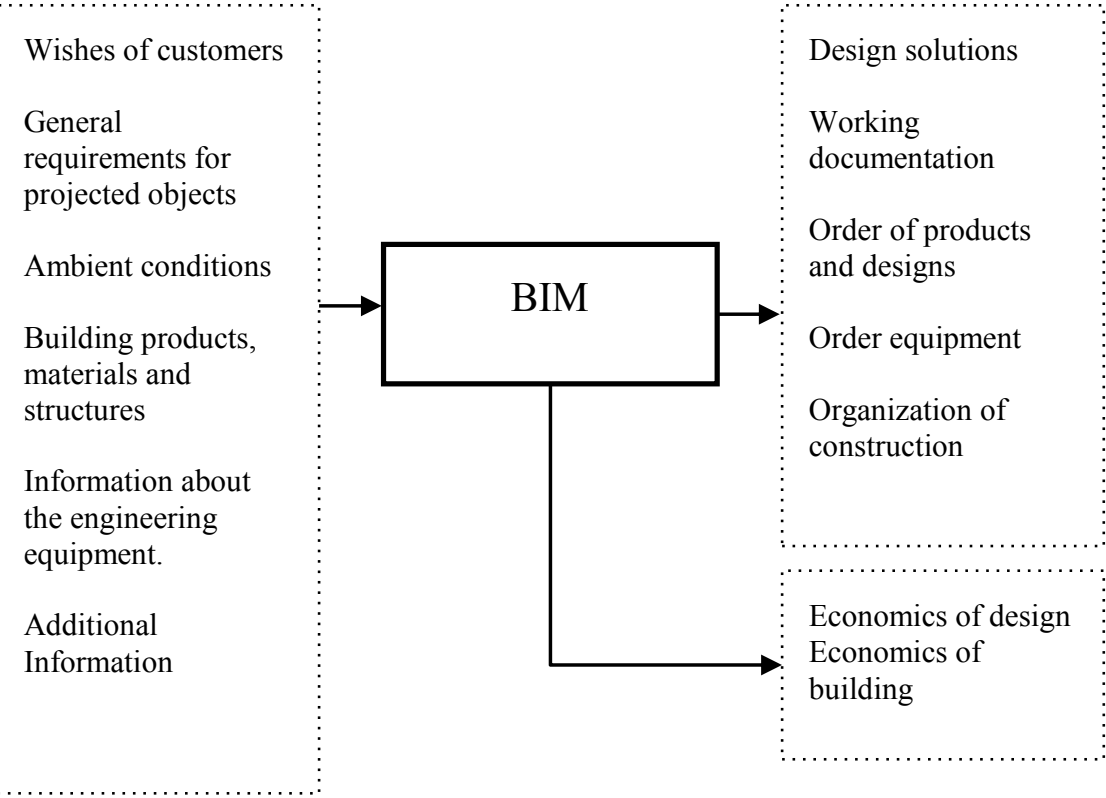

Fig. 1. BIM in organization of construction. 


\section{Statistics}

From practice, you can give an example of the use of information technology. The practice of the design institute in the design of Zenit Arena in St. Petersburg showed that the use of BIM technologies in designing objects of increased complexity can save up to $15 \%$ of the construction costs of the facility as a whole.

The Autodesk study provides the following results: technical failures are detected on time, thereby reducing costs by $10 \%$; project implementation time is reduced by $7-15 \%$; and also increases the accuracy of estimated calculations by $3 \%$; important is the fact that almost $80 \%$ can reduce the development of construction estimates, and it is also important that the reduced marriages and construction waste by $30 \%$. In this case, there is a cardinal increase in transparency, it becomes possible to more accurately assess the effectiveness and targeted spending of budgetary funds.

The Ministry of Construction of the Russian Federation cites its research results: the introduction of information modeling technologies improves a number of performance indicators: $30 \%$ reduction in construction and operation costs; up to $40 \%$ reduces errors in project documentation; up to $50 \%$ reduces the time of project implementation; 6 times reduces the time to check the model; 4 times reduces budget planning errors; up to $90 \%$ reduces the time of coordination; reduces construction time by $10 \%$; reduces design time by $20-50 \%$.

Also, consulting company McGraw Hill Construction conducted a survey among companies in the construction industry and found out what advantages they got from implementing BIM. Thus, the study showed the following results: $41 \%$ of surveyed companies noted a reduction in the number of errors after the introduction of technology. In turn, $35 \%$ and $32 \%$ paid attention to improving communication between managers and designers and improving the image of the enterprise, respectively.

\section{Conclusion}

Today, a general regulatory and legislative framework has been created for the work of the entire construction industry. The Ministry of Construction of Russia has formulated the requirements for the application of BIM technologies, has also prepared and submitted for approval to the government a list of documents that need to be developed or modified.

Based on the above, the main advantages of implementing BIM should be noted:

-specialists from different areas work with the same design data;

-the gaps and errors in the collected information are much reduced;

-development of a rich and informational model, where all the calculations of the object under construction are collected;

-modeling, management and control occur throughout the entire life cycle of an object;

-the ability to produce an experimental survey of the model under certain conditions;

-the time and cost of the project of a building or structure are reduced in many ways;

All of these benefits increase the competitiveness of the construction on a global scale.

As a result of the use of BIM technologies, we develop a project longer, but we save a lot of time on developing project documentation, and also minimize the number of errors, which leads to an increase in the speed of project coordination. With the help of BIM programs, a designer using a ready-made $3 \mathrm{D}$ model develops project documentation. As a result, the use of BIM technology instead of standard classical technologies reduces the total amount of time (project development, project documentation and project coordination) by $20-50 \%$. Using BIM programs, the designer using ready-made 3D model develops project documentation. Information modeling in the process of developing a project gives the user more information than can be seen in a real building, since it provides data on the 
internal details of the object (hidden works). The program stores information about the materials used in construction. This solves a huge number of problems in the further operation of the building. Also a big advantage of BIM technology is that you can visually find yourself in a designed building and understand all the details of a future building. This helps to minimize the number of errors in the design of the building.

Further development of information modeling technology, in our opinion, is OPEN BIM - this is a universal approach to the joint design, construction and operation of buildings and structures, using open work processes and standards. Such companies as graphisoft, tekla, nemetschek, allplan, scia, vectorworks, Trimble and data design system joined the OPEN BIM initiative. At the core of the OPEN BIM approach is the open building SMART data model. Alliance members have initiated a global OPEN BIM promotion program in the AIS industry. Industry Foundation Classes is an open format of a building information model developed by building SMART to facilitate interaction in the construction industry. Its development is not controlled by a single company or group of companies.

\section{References}

1. P.M. Bosch-Sijtsema, P. Gluch, A.A. Sezer, Automation in Construction 97, 44-51 (2019) ISSN 0926-5805, https://doi.org/10.1016/j.autcon.2018.10.024.

2. A. Volkov, P. Chelyshkov, D. Lysenko, Procedia Engineering 153, 828-832 (2016) ISSN 1877-7058, https://doi.org/10.1016/j.proeng.2016.08.250

3. J. Fountain, S. Langar, Automation in Construction 95, 107-117 (2018) ISSN 09265805, https://doi.org/10.1016/j.autcon.2018.06.009

4. X. Zheng, Y. Lu, Y. Li, Y. Le, J. Xiao, Automation in Construction 99, 91-108 (2019) ISSN 0926-5805, https://doi.org/10.1016/j.autcon.2018.12.001

5. W. Solihin, C. Eastman, Y.-Ch. Lee, D.-H. Yang, Automation in Construction 84, 367383 (2017) ISSN 0926-5805, https://doi.org/10.1016/j.autcon.2017.10.002

6. E.S. Rakhmatullina, Russian Journal of Entrepreneurship 18(19), 2866 (2017) doi: 10.18334 / gr.18.19.38345

7. A.E. Mamaev, V.V. Sharmanov, Yu.S. Zolotova, V.A. Svintsitsky, G.S. Gorodnyuk, Actual problems of the humanities and natural sciences 1-3, 83-87 (2016)

8. V. Batishev, Sport build 7, 20-27 (2015) 